\title{
Degradação e sorção de ametrina em dois solos com aplicação de vinhaça(1)
}

\author{
Fábio Prata(2), Arquimedes Lavorenti( ${ }^{(3)}$, Jussara Borges Regitano(4) \\ e Valdemar Luís Tornisielo(4)
}

\begin{abstract}
Resumo - Este trabalho teve o objetivo de avaliar os efeitos da adição de vinhaça nos processos de degradação e sorção do herbicida ametrina em solos das classes Terra Roxa Estruturada (TR) e Latossolo Vermelho-Amarelo (LV). No estudo da degradação foi instalado um experimento, em delineamento inteiramente casualizado arranjado em fatorial 2 (solos) x 3 (doses de vinhaça: 0,100 e $200 \mathrm{~m}^{3} \mathrm{ha}^{-1}$ ), que foi conduzido por 120 dias. A mineralização foi avaliada por radiorrespirometria. Após os 120 dias, o herbicida foi extraído do solo e detectado em "radio-scanner". Paralelamente, foi conduzido um ensaio para avaliação do efeito das doses de vinhaça juntamente com a ametrina na atividade microbiana, pH e C orgânico do solo. O experimento de sorção foi realizado com os mesmos tratamentos empregados no estudo de degradação, utilizando-se cinco concentrações do herbicida. A degradação da ametrina foi maior na presença de $100 \mathrm{~m}^{3} \mathrm{ha}^{-1}$ de vinhaça. A adição do resíduo contribuiu para o aumento da atividade microbiana e do $\mathrm{pH}$. A ametrina foi pouco sorvida nos dois solos, não apresentando influência da adição da vinhaça.
\end{abstract}

Termos para indexação: herbicidas, resíduos, matéria orgânica, biodegradação.

\section{Degradation and sorption of ametryne in two soils with vinasse application}

\begin{abstract}
The aim of this study was to evaluate the effects of vinasse (100 and $\left.200 \mathrm{~m}^{3} \mathrm{ha}^{-1}\right)$ on the degradation and sorption of ametryne in Rhodudalf and Haplorthox soils. For the degradation study an experiment was carried out in a completely randomized design with a factorial experiment of 2 (soils) $\mathrm{x}$ 3 (vinasse doses: 0,100 and $200 \mathrm{~m}^{3} \mathrm{ha}^{-1}$ ), that was carried by 120 days. The mineralization was evaluated by radiorespirometry. At the end of the incubation (after 120 days), the herbicide was extracted from the soils and detected in the radio-scanner. In parallel, another experiment was carried out in order to evaluate the effect of the vinasse doses and herbicide on the microbial activity, $\mathrm{pH}$ and organic carbon content of the soil. The sorption experiment was carried out under the same conditions as the degradation study, with five herbicide concentrations. The ametryne degradation was higher in the presence of $100 \mathrm{~m}^{3} \mathrm{ha}^{-1}$ of vinasse. The vinasse addition increased the microbial activity and the $\mathrm{pH}$. The sorption of ametryne was low and not affected by vinasse.
\end{abstract}

Index terms: herbicides, residues, organic matter, biodegradation.

(1) Aceito para publicação em 27 de setembro de 2000. Extraído da Dissertação de Mestrado, apresentada pelo primeiro autor à Escola Superior de Agricultura Luiz de Queiroz (ESALQ), Piracicaba, SP.

(2)ESALQ, Caixa Postal 9, CEP 13418-900 Piracicaba, SP Bolsista da FAPESP. E-mail: fprata@carpa.ciagri.usp.br

${ }^{(3)}$ ESALQ, Dep. de Ciências Exatas.

E-mail: lavoren@carpa.ciagri.usp.br

${ }^{(4)}$ Centro de Energia Nuclear na Agricultura, Caixa Postal 96, CEP 13400-970 Piracicaba, SP. E-mail: regitano@cena.usp.br vltornis@carpa.ciagri.usp.br

\section{Introdução}

A ametrina (2-etilamina-4-isopropilamina-6metiltio-s-2,4,6-trazina) é um herbicida pertencente ao grupo das s-triazinas utilizado no controle de plantas daninhas na cultura da cana-de-açúcar no Brasil. Esta molécula apresenta propriedades físico-químicas que lhe confere uma elevada persistência no ambiente (Costa, 1992), podendo persistir por até seis 
meses no solo (Rodrigues \& Almeida, 1995). Sua aplicação, na maioria das vezes, é feita em pré-emergência e geralmente precede em alguns dias a aplicação da vinhaça em soqueiras de cana.

Estudos de aplicação de herbicidas utilizando a vinhaça para o preparo da calda já foram realizados. Buss et al. (1978) verificaram que o efeito residual de controle da ametrina foi prolongado quando aplicada com a vinhaça. Os autores sugeriram que o resíduo orgânico estaria sorvendo o herbicida, que era liberado gradativamente. Entretanto, problemas de aplicação impediram que este manejo se perpetuasse.

A aplicação de vinhaça em soqueiras de cana-deaçúcar como fonte de nutrientes é muito comum no Brasil. Este resíduo do processo de fermentação do álcool consiste numa fonte de carbono solúvel, sendo o glicerol seu principal constituinte (Rodella et al., 1983). Os trabalhos têm mostrado que a adição da vinhaça modifica temporariamente alguns atributos químicos e biológicos do solo, como o pH, o C orgânico, a acidez trocável (Camargo et al., 1987; Reis, 1998), a atividade e a biomassa microbiana (Martinez Cruz et al., 1987; Minhoni \& Cerri, 1987), os quais interferem diretamente no comportamento de herbicidas no solo, tanto na sorção como na degradação (Bollag \& Liu, 1990).

Embora os efeitos da matéria orgânica no comportamento de pesticidas no solo venham sendo amplamente discutidos, não existem relatos na literatura sobre os efeitos da adição de vinhaça no comportamento de herbicidas. No entanto, pelas alterações de alguns atributos químicos e microbiológicos do solo provocadas pela adição da vinhaça, é possível que sua aplicação ao solo venha contribuir com a maior persistência da ametrina, proporcionada por um aumento na sua sorção. Por outro lado, o fato de a vinhaça promover o aumento da atividade e biomassa microbiana poderia vir a contribuir com a aceleração da degradação desse herbicida no solo.

O presente trabalho objetivou estudar o efeito da vinhaça nos processos de degradação e sorção do herbicida ametrina, nos solos da classe Terra Roxa
Estruturada, textura muito argilosa e Latossolo Vermelho-Amarelo, textura média arenosa.

\section{Material e Métodos}

Os experimentos foram conduzidos no Laboratório de Ecotoxicologia do Centro de Energia Nuclear na Agricultura (CENA), em Piracicaba, SP. Foram coletadas amostras de solo $(0-10 \mathrm{~cm})$ de uma Terra Roxa Estruturada (TR) e de um Latossolo Vermelho-Amarelo (LV) no Município de Piracicaba, e utilizou-se para os estudos, a fração terra fina secada ao ar (TFSA).

As análises químicas e granulométricas dos solos foram realizadas de acordo com Raij \& Quaggio (1983) e Camargo et al. (1986), respectivamente, tendo sido o carbono orgânico determinado pelo método da combustão (Nelson \& Sommers, 1982) (Tabela 1).

O herbicida ametrina (2-etilamina-4-isopropilamina6-metiltio-s-2,4,6-trazina), grau técnico, foi empregado nos ensaios com seu correspondente radiomarcado uniformemente nos carbonos do anel $\left({ }^{14} \mathrm{C}\right)$, com atividade específica de $1,35 \mathrm{MBq} \mathrm{mg}^{-1}$, pureza radioquímica de $99 \%$ e solubilidade em água de $42 \mathrm{mg} \mathrm{L}^{-1}$, fornecido pelo Laboratório de Ecotoxicologia do CENA.

As doses de vinhaça empregadas nos experimentos, equivalentes a 100 e $200 \mathrm{~m}^{3} \mathrm{ha}^{-1}$, foram baseadas nas recomendações para soqueiras de cana-de-açúcar. Para tal, foi determinada a densidade dos solos, de acordo com o método do torrão (Blake \& Hartge, 1986), sendo igual a 1,0 e $1,2 \mathrm{~g} \mathrm{~cm}^{-3}$ para solo TR e LV, respectivamente. A espessura da camada de solo considerada para os cálculos foi de $10 \mathrm{~cm}$.

Antes da aplicação do herbicida, a vinhaça foi adicionada às amostras de terra, que ficaram incubadas ao ar livre por quatro dias, período aproximado que antecede a aplicação da ametrina às soqueiras de cana-de-açúcar. Essa aplicação foi feita diretamente nos frascos (parcelas), nos ensaios de degradação e atividade microbiana, e em bandejas de plástico, das quais foram retiradas as alíquotas de terra para o ensaio de sorção.

$\mathrm{O}$ experimento de degradação foi conduzido em delineamento inteiramente casualizado, arranjado em fatorial

Tabela 1. Características químicas e granulométricas dos solos Terra Roxa Estruturada (TR) e Latossolo VermelhoAmarelo (LV)

\begin{tabular}{|c|c|c|c|c|c|c|c|c|c|c|c|c|}
\hline Solo & $\mathrm{pH}_{\mathrm{H}_{2} \mathrm{O}}$ & C org. & $\mathrm{P}$ & $\mathrm{K}$ & $\mathrm{Ca}$ & $\overline{\mathrm{Mg}}$ & $\mathrm{Al}$ & $\mathrm{H}+\mathrm{Al}$ & $\mathrm{T}$ & Areia & Silte & Argila \\
\hline & & $\left(\mathrm{g} \mathrm{dm}^{-3}\right)$ & $\left(\mathrm{mg} \mathrm{dm}^{-3}\right)$ & ----- & ---- & ----- & $\mathrm{ol}_{\mathrm{c}}$ & -3)--- & --------- & -------- & $\left(\mathrm{g} \mathrm{kg}^{-1}\right.$ & - \\
\hline TR & 6,9 & 14,3 & 23 & 7,4 & 49 & 26 & 0 & 22 & 104,4 & 280 & 120 & 600 \\
\hline LV & 6,0 & 4,0 & 6 & 0,7 & 14 & 5 & 1 & 38 & 57,7 & 700 & 60 & 240 \\
\hline
\end{tabular}


2 (solos) x 3 (doses de vinhaça: 0,100 e $\left.200 \mathrm{~m}^{3} \mathrm{ha}^{-1}\right)$, em triplicata. A vinhaça possuía $\mathrm{pH}$ de 4,3 e os seguintes componentes em g L ${ }^{-1}: 7,47$ de C orgânico; 0,10 de $\mathrm{P}_{2} \mathrm{O}_{5} ; 5,10$ de $\mathrm{K}_{2} \mathrm{O} ; 1,18$ de $\mathrm{Ca} ; 0,42$ de $\mathrm{Mg} ; 0,96$ de $\mathrm{S} ; 0,70$ de $\mathrm{Ne}$ $\mathrm{C} / \mathrm{N}$ de 11. O C orgânico foi determinado conforme Nelson \& Sommers (1982).

$\mathrm{O}$ ensaio foi desenvolvido em frascos de vidro com boca larga, hermeticamente fechados, com capacidade para $500 \mathrm{~mL}$, utilizando-se uma massa de terra de $100 \mathrm{~g}$ por frasco.

A concentração do herbicida utilizada foi de $0,25 \mathrm{mg}$ por $100 \mathrm{~g}^{-1}$ de solo $\left(3,0 \mathrm{~kg} \mathrm{ha}^{-1}\right.$ de ingrediente ativo, dose máxima utilizada no campo), com radioatividade de $11,33 \mathrm{kBq}$ por $100 \mathrm{~g}$ de solo.

O ensaio foi conduzido por 120 dias, no escuro, a $25 \pm 2^{\circ} \mathrm{C}$, com a capacidade de campo dos solos mantida a $60 \%$. $\mathrm{O}^{14} \mathrm{CO}_{2}$ desprendido do herbicida foi coletado por uma solução de $\mathrm{NaOH} 0,2 \mathrm{~mol} \mathrm{~L}^{-1}$, e as avaliações foram feitas nos dias $0,1,7,14,21,28,35,42,49,56,63$ e 120 após a aplicação. A radioatividade foi determinada por cintilação líquida (Mesquita \& Ruegg, 1984).

Ao final do período de incubação, o herbicida remanescente foi extraído com metanol, sendo a primeira extração por um período de duas horas, e as duas posteriores, por 30 minutos. A detecção da fração do herbicida extraído foi feita por cromatografia de camada delgada (TLC), utilizando-se tolueno-clorofórmio-acetato de etila $(2: 2: 1 \mathrm{v} / \mathrm{v} / \mathrm{v})$ como sistema solvente, e a leitura foi feita em "radio-scaner" (Automatic TLC-Linear Analyzer Berthold). Após a extração, alíquotas de amostras de solo foram oxidadas para o fechamento do balanço de radioatividade.

Para a avaliação da atividade microbiana, foi instalado um experimento em arranjo fatorial $2 \times 3 \times 2$, sendo: dois solos (TR e LV), três doses de vinhaça $(0,100$ e $\left.200 \mathrm{~m}^{3} \mathrm{ha}^{-1}\right)$, com e sem herbicida. As avaliações foram feitas nos dias $0,4,11,18,25,32$ e 63 , pelo método da ${ }^{14} \mathrm{C}$-glicose (Freitas et al., 1979). Nesses mesmos períodos foram realizadas análises de $\mathrm{pH}$ em água.

Os tratamentos utilizados no ensaio de sorção foram os mesmos empregados para o estudo da degradação. No entanto, foram utilizadas cinco concentrações do herbicida para cada tratamento: $2,47,5,0,7,5,10,0 \mathrm{e}$ $12,5 \mu \mathrm{g} \mathrm{mL} \mathrm{m}^{-1}$, com radioatividade de $0,33 \mathrm{kBq} \mathrm{mL}^{-1}$. Essas cinco concentrações foram utilizadas para extrair os coeficientes de Freundlich, mediante as isotermas de sorção. A relação solo/ $\mathrm{CaCl}_{2} 0,01 \mathrm{~mol} \mathrm{~L}^{-1}$ foi de $1 / 10$, e o tempo de agitação de equilíbrio, de 24 horas.

$\mathrm{O}$ experimento foi conduzido em triplicata, com um branco (herbicida sem solo) para cada concentração do herbicida, que foi utilizado como padrão.

Por meio do modelo matemático linearizado de Freundlich, descrito abaixo, foram determinadas as cons- tantes de Freundlich para a adsorção $\left(k_{f}\right)$ e o grau de linearidade $(1 / n)$.

$\log \mathrm{S}=\log \mathrm{K}_{\mathrm{f}}+1 / \mathrm{n} \log \mathrm{C}_{\mathrm{e}}$,

em que: $\mathrm{S}$ é a quantidade do herbicida sorvido no solo $\left(\mu \mathrm{g} \mathrm{g}^{-1}\right) ; \mathrm{C}_{\mathrm{e}}$, a concentração do herbicida na solução em equilíbrio com o solo $\left(\mu \mathrm{g} \mathrm{mL}^{-1}\right), \mathrm{K}_{\mathrm{f}}$, o coeficiente de Freundlich; $1 / \mathrm{n}$, o grau de linearidade da sorção.

Foram realizadas análises de $\mathrm{C}$ orgânico por combustão seca nas amostras de terra pré-incubadas com $0,100 \mathrm{e}$ $200 \mathrm{~m}^{3} \mathrm{ha}^{-1}$ de vinhaça, das quais foram retiradas as subamostras para o estudo da sorção. Essas análises foram procedidas quatro dias após a aplicação da vinhaça, com a finalidade de subsidiar explicações para possíveis resultados de sorção da ametrina em função da aplicação da vinhaça.

As análises estatísticas foram realizadas através do programa SAS. Foram feitas análises de variância e comparação de médias pelo teste $\mathrm{t}$, para o desprendimento de ${ }^{14} \mathrm{CO}_{2}$ acumulado, e foram calculadas as médias e seus respectivos desvios-padrões, relativos às constantes de Freundlich, $\mathrm{pH}$ e atividade microbiana.

\section{Resultados e Discussão}

A adição de vinhaça aos solos proporcionou um aumento significativo da taxa de desprendimento de ${ }^{14} \mathrm{CO}_{2}$ da ametrina, contribuindo para a maior mineralização desta molécula (Tabela 2).

Considerando os primeiros 28 dias após a aplicação do herbicida, período utilizado para a classificação de persistência de pesticidas para fins de regis-

Tabela 2. Porcentagem acumulada de ${ }^{14} \mathrm{CO}_{2}$ desprendido do herbicida ametrina aos 28, 63 e 120 dias após a aplicação de 0,100 e $200 \mathrm{~m}^{3} \mathrm{ha}^{-1}$ de vinhaça nos solos Terra Roxa Estruturada (TR) e Latossolo Vermelho Amarelo (LV) ${ }^{(1)}$

\begin{tabular}{ccrrr}
\hline $\begin{array}{c}\text { Dias após } \\
\text { aplicação }\end{array}$ & Solo & \multicolumn{3}{c}{ Vinhaça $\left(\mathrm{m}^{3} \mathrm{ha}^{-1}\right)$} \\
\cline { 3 - 5 } & & \multicolumn{1}{c}{0} & 100 & 200 \\
\hline 28 & TR & $0,98 \mathrm{cA}$ & $1,22 \mathrm{bA}$ & $1,72 \mathrm{aA}$ \\
& LV & $0,09 \mathrm{aB}$ & $0,20 \mathrm{aB}$ & $0,04 \mathrm{aB}$ \\
& & & & \\
63 & TR & $4,47 \mathrm{bA}$ & $4,95 \mathrm{bA}$ & $7,17 \mathrm{aA}$ \\
& LV & $0,21 \mathrm{bB}$ & $2,11 \mathrm{aB}$ & $0,52 \mathrm{bB}$ \\
& & & & \\
120 & TR & $24,83 \mathrm{bA}$ & $28,67 \mathrm{aA}$ & $22,94 \mathrm{bA}$ \\
& LV & $0,43 \mathrm{bB}$ & $7,55 \mathrm{aB}$ & $1,84 \mathrm{bB}$ \\
\hline
\end{tabular}

${ }^{(1)}$ Médias seguidas pelas mesmas letras, minúsculas nas linhas e maiúsculas nas colunas, não diferem entre si pelo teste $t$, a $1 \%$ de probabilidade. 
tro no IBAMA (Brasil, 1988), as doses de vinhaça contribuíram de maneira semelhante para a aceleração da mineralização da molécula no solo TR, chegando ao ponto de alterar sua classificação de persistência, que passou de alta para média. O mesmo não foi observado no solo LV.

Esta alteração na classificação de persistência da ametrina também foi observada por Costa (1992), passando de alta para média nos tratamentos que receberam adição de rizosfera de cana proveniente de áreas que vinham sendo tratadas anteriormente com este herbicida. Esse efeito foi explicado pelo aumento da atividade microbiana.

A persistência da ametrina em solos é classificada como média (Rodrigues \& Almeida, 1995). Entretanto, estes autores sugerem que esta classificação pode variar conforme o tipo de solo e as condições climáticas. Nos estudos de Compte (1997), a persistência foi classificada como alta.

Até 63 dias após a aplicação, foi observado um efeito maior da dose de $200 \mathrm{~m}^{3} \mathrm{ha}^{-1}$ no solo TR, que foi superado pela dose de $100 \mathrm{~m}^{3} \mathrm{ha}^{-1}$ no final do experimento. Para o LV, a maior contribuição da dose inferior de vinhaça em relação à maior já pode ser observada a partir dos 63 dias da aplicação (Tabela 2). $\mathrm{O}$ aumento da atividade microbiana nos dois solos com a adição das doses de vinhaça foi progressivo (Figura 1), o que pode sustentar, em parte, a aceleração da mineralização do herbicida na presença do resíduo, mas não explica o maior efeito da dose menor de vinhaça.

A maior contribuição da dose de $100 \mathrm{~m}^{3} \mathrm{ha}^{-1} \mathrm{em}$ comparação à de $200 \mathrm{~m}^{3} \mathrm{ha}^{-1}$ na aceleração da mineralização da ametrina pode estar relacionada com a inibição de grupos de microorganismos específicos capazes de atuar na degradação desta molécula quando a vinhaça é aplicada na maior dose.

$\mathrm{O}$ aumento da atividade microbiana com a adição do resíduo (Figura 1) também foi observado por outros autores (Martinez Cruz et al., 1987; Minhoni \& Cerri, 1987), e pode ser explicado pelo fornecimento de energia e $\mathrm{C}$ aos microorganismos quimiorganotróficos por meio da matéria orgânica da vinhaça, que se constitui numa fonte de $\mathrm{C}$ solúvel e prontamente disponível. Segundo Rodella et al. (1983), a maior parte do C da vinhaça está na forma de glicerol, proveniente de rotas alternativas durante a fermentação na produção do álcool. Na célula microbiana, o glicerol pode passar a diidroxicetona, que é incorporada à via glicolítica do metabolismo microbiano (Lehninger, 1985).

Acréscimos no $\mathrm{pH}$ foram observados na presença das doses de vinhaça (Figura 2). Estes acréscimos, bastante discutidos na literatura (Camargo et al., 1987; Mattiazzo \& Glória, 1987; Reis, 1998), também poderiam estar influenciando na alteração do comportamento da ametrina, por favorecer o desenvolvimento de determinados grupos de microorganismos responsáveis pela sua degradação, e também por contribuir com o processo de hidroxilação deste herbicida. Este processo pode ter ocorrido nos grupos etilamino,
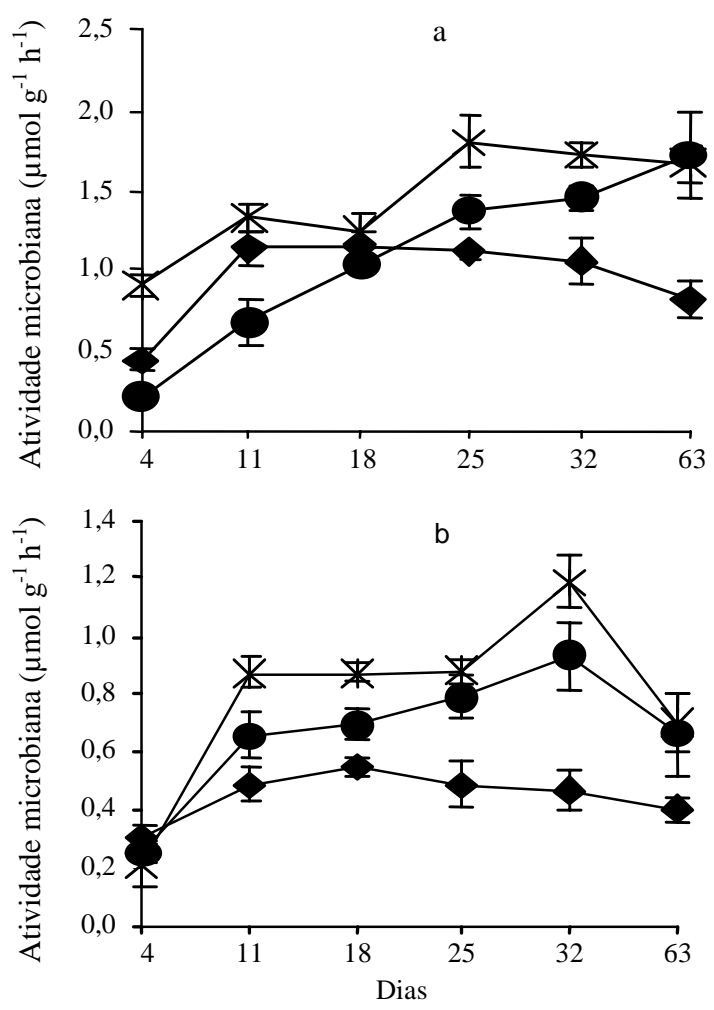

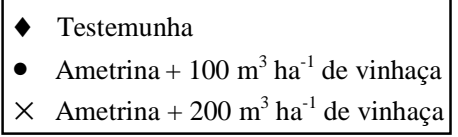

Figura 1. Atividade microbiana nos solos Terra Roxa Estruturada (a) e Latossolo Vermelho-Amarelo (b) tratados com vinhaça e ametrina. As barras indicam o desviopadrão da média. 
isopropilamino e metiltio da ametrina. Cook \& Hütter (1982) observaram uma dessulfuração da ametrina e a formação do metabólito hidroxiametrina, em culturas de bactérias.

Segundo Bollag \& Liu (1990), a hidroxilação é um dos principais processos envolvidos na degradação de herbicidas pelo aumento da polaridade da molécula.

A aceleração da degradação da ametrina com a adição do resíduo orgânico pode ser uma evidência de co-metabolismo, ou seja, a transformação do herbicida por reações metabólicas, onde o substrato
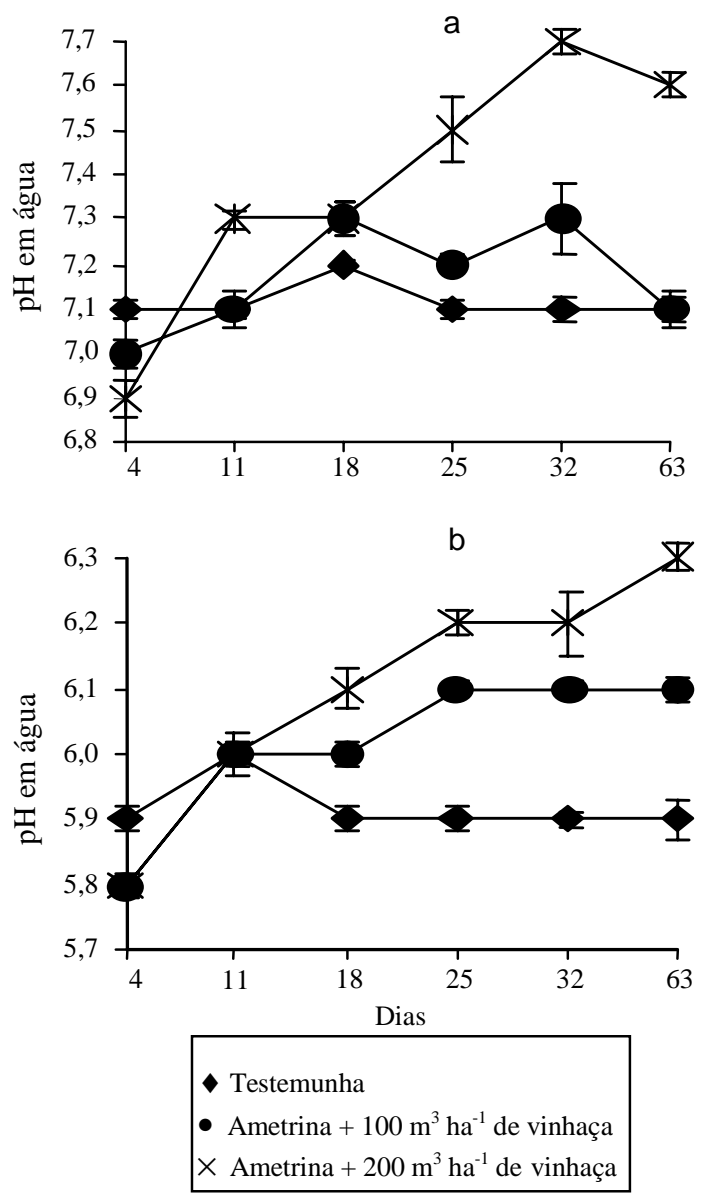

Figura 2. Valores de $\mathrm{pH}$ em água nos solos Terra Roxa Estruturada (a) e Latossolo Vermelho-Amarelo (b), incubados com vinhaça e ametrina. As barras indicam o desvio-padrão da média. não serve como fonte de energia aos microorganismos (Bollag \& Liu, 1990). Costa (1992) também observou a possível ocorrência do co-metabolismo para a ametrina.

Para todos os tratamentos, a extração foi quase a totalidade da fração disponível do herbicida (Tabela 3), o que indica que a molécula não tende à formação de resíduo ligado, que, de acordo com a União Internacional de Química Pura e Aplicada (IUPAC), é o nome dado à interação entre espécies químicas originadas da transformação de pesticidas com as substâncias húmicas do solo, pois estes resíduos não são passíveis de extração por métodos que não alterem significativamente a natureza da molécula (Führ, 1987). Isto pode implicar que a utilização do parâmetro dissipação para inferências sobre seu comportamento pode ser um tanto quanto perigoso, pois a fração residual da molécula está em equilíbrio com a solução do solo, e pode ser lixiviada ou absorvida por plantas, caracterizando efeitos residuais de controle.

Após a extração da fração residual não foi detectada a ocorrência de metabólitos por TLC. Apenas o composto com valor de relação de frente (Rf) de 0,29 (produto original) foi detectado. Compte (1997) também não observou a formação de metabólitos em seus estudos de degradação de ametrina; todavia, o sistema solvente utilizado foi acetonitrila:água:ácido fórmico $(94: 5: 1 \mathrm{v} / \mathrm{v} / \mathrm{v})$.

A baixa porcentagem de mineralização da molécula, e o fato de esta não ser metabolizada e não formar resíduo ligado, deve merecer mais atenção nos estudos de química ambiental de solos, pois isto pode ser um possível indicativo de problemas ambientais.

As doses de vinhaça não apresentaram efeito nos processos de sorção envolvendo a ametrina e os colóides dos solos (Tabela 4). Entretanto, o herbicida foi mais sorvido pelo solo TR do que pelo LV, apesar de os valores das constantes de Freundlich $\left(\mathrm{K}_{\mathrm{f}}\right)$ serem baixos em ambos os casos (Tabela 4).

A ametrina é um herbicida de caráter básico com $\mathrm{pK}_{\mathrm{a}}$ em torno de 4,0 (Weber, 1970). Todavia, no presente caso, o $\mathrm{pH}$ dos solos está acima do $\mathrm{pK}_{\mathrm{a}}$ da molécula em mais de duas unidades, isto é, praticamente toda a ametrina encontra-se na fase molecular. Isto indica que, provavelmente, a sorção deste herbicida não esteja ocorrendo pela ação de forças 
Tabela 3. Porcentagem de recuperação do herbicida ametrina nos solos Terra Roxa Estruturada e Latossolo VermelhoAmarelo tratados com 0, 100 e $200 \mathrm{~m}^{3}$ ha-1 de vinhaça, aos 120 dias após a aplicação.

\begin{tabular}{|c|c|c|c|c|c|c|}
\hline \multirow[t]{2}{*}{${ }^{14} \mathrm{CO}_{2}(\%)$} & \multicolumn{6}{|c|}{ Vinhaça $\left(\mathrm{m}^{3} \mathrm{ha}^{-1}\right)$} \\
\hline & 0 & 100 & 200 & 0 & 100 & 200 \\
\hline & \multicolumn{6}{|c|}{-------------Terra Roxa Estruturada------------- } \\
\hline Desprendido & 24,83 & 28,67 & 22,94 & 0,43 & 7,54 & 1,89 \\
\hline Extraído & 69,04 & 65,59 & 71,85 & 94,16 & 103,08 & 89,73 \\
\hline Não-extraído & 14,06 & 10,98 & 4,10 & 1,40 & 3,55 & 3,80 \\
\hline Recuperado & 107,93 & 105,24 & 98,89 & 95,99 & 114,17 & 95,42 \\
\hline
\end{tabular}

Tabela 4. Parâmetros de Freundlich para a capacidade de adsorção do herbicida ametrina nos solos da classe Terra Roxa Estruturada(TR) e Latossolo Vermelho-Amarelo (LV) tratados com vinhaça.

\begin{tabular}{lcccc}
\hline Solos & $\begin{array}{c}\text { Vinhaça } \\
\left(\mathrm{m}^{3} \mathrm{ha}^{-1}\right)\end{array}$ & \multicolumn{2}{c}{$\begin{array}{c}\text { Parâmetros de } \\
\text { Freundlich }\end{array}$} & $\mathrm{R}^{2}$ \\
\cline { 3 - 4 } & & \multicolumn{2}{c}{$\mathrm{K}_{\mathrm{f}}$} & \\
\hline TR & 0 & 2,7 & 0,46 & 0,98 \\
& 100 & 2,9 & 0,49 & 0,98 \\
LV & 200 & 2,2 & 0,61 & 0,98 \\
& 0 & 1,6 & 0,51 & 0,96 \\
& 100 & 1,6 & 0,52 & 0,88 \\
& 200 & 1,2 & 0,65 & 0,99 \\
\hline
\end{tabular}

${ }^{(1)} \mathrm{K}_{\mathrm{f}}$ : constante de Freundlich (média de 3 repetições, $\mathrm{CV} \leq 11,64 \%$ ); $1 / \mathrm{n}$ : grau de linearidade.

eletrostáticas. Assim, sugere-se que a interação hidrofóbica com as substâncias húmicas deva ser considerada, visto a baixa solubilidade em água da molécula e os maiores valores de $\mathrm{K}_{\mathrm{f}}$ no solo com maior teor de matéria orgânica (Tabela 4).

Os valores de $\mathrm{K}_{\mathrm{f}}$ (Tabela 4) são condizentes aos encontrados por Yamane \& Green (1972) e Furlan (1992), que variaram de 1,84 a 15,77 em solos com pH em água entre 4,8 e 6,5, respectivamente. Os valores de $1 / \mathrm{n}$ (Tabela 4 ) também são condizentes com os obtidos por Furlan (1992).

A não-interferência da adição da vinhaça nos processos de sorção do herbicida pode ser explicada, pelo fato de a matéria orgânica deste resíduo ser constituída principalmente de glicerol, que é prontamente disponível aos microrganismos quimiorganotróficos do solo. Assim, após quatro dias da adição da vinhaça - período após o qual foi realizada a aplicação do herbicida -, grande parte da matéria orgânica do resíduo já havia sido mineralizada. Isto pode ser observado através das determinações de C orgânico (Tabela 5) das amostras de solo com e sem adição de vinhaça, quatro dias após sua aplicação.
Tabela 5. Carbono orgânico em solos da classe Terra Roxa Estruturada (TR) e Latossolo Vermelho-Amarelo (LV), quatro dias após a aplicação da vinhaça( ${ }^{(1)}$.

\begin{tabular}{ccc}
\hline Vinhaça & $\begin{array}{c}\text { Terra Roxa } \\
\text { Estruturada }\end{array}$ & $\begin{array}{c}\text { Latossolo } \\
\text { Vermelho-Amarelo }\end{array}$ \\
\hline$\left(\mathrm{m}^{3} \mathrm{ha}^{-1}\right)$ & ----------- \\
0 & 14,8 & 3,8 \\
100 & 15,1 & 3,8 \\
200 & 14,5 & 4,0 \\
\hline $\mathrm{CV}(\%)$ & 6,95 & 13,86 \\
\hline
\end{tabular}

(1)Médias de duas repetições.

\section{Conclusões}

1. A adição de vinhaça ao solo faz com que o processo de mineralização da ametrina seja acelerado.

2. Não há formação de metabólitos no processo de degradação da ametrina.

3. A ametrina é pouco sorvida ao solo, e não tende à formação de resíduo ligado.

4. A adição de vinhaça ao solo não interfere na sorção da ametrina.

\section{Referências}

BLAKE, G. R.; HARTGE, K. H. Bulk density. In: KLUTE, A. (Ed.). Methods of soil analysis: physical and mineralogical methods. Madison : American Society of Agronomy/Soil Science Society of America, 1986. pt 1, p. 363-376. (Agronomy Series, 9).

BOLLAG J. M.; LIU, S. Y. Biological transformation processes of pesticides. In: CHENG H. H. (Ed.). Pesticides in the soil environment: processes, impacts and modeling. Madison: Soil Science Society of America, 1990. p. 169-211. 
BRASIL. Ministério do Interior. Manual de testes para avaliação da ecotoxicidade de agentes químicos. Brasília : Secretaria Especial do Meio Ambiente, 1988. 408 p.

BUSS, A.; GLÓRIA, N. A.; JACINTO, O. A. Viabilidade do uso de herbicidas em mistura com vinhaça para o controle de plantas daninhas em soqueiras de cana-de-açúcar. Planta Daninha, Campinas, v. 2, p. 49-56, 1978.

CAMARGO, O. A.; MONIZ, A. C.; JORGE, J. A.; VALADARES, J. M. Métodos de análise química, mineralógica e física de solos do Instituto Agronômico de Campinas. Campinas : Instituto Agronômico, 1986. 94 p. (IAC. Boletim Técnico, 106).

CAMARGO, O. A.; VALADARES, J. M. A. S.; BERTON, R. S.; TEÓFILO SOBRINHO, J.; MENK, J. R. F. Alteração de características químicas de um latossolo vermelho-escuro distrófico pela aplicação de vinhaça. Campinas : Instituto Agronômico, 1987. 23 p. (IAC. Boletim Científico, 9).

COMPTE, V. X. Avaliação de metodologias de coleta de ${ }^{14} \mathrm{CO}_{2} \mathrm{em}$ estudos de biodegradação de agroquímicos em solos. Piracicaba : USP-CENA, 1997. 55 p. Dissertação de Mestrado.

COOK, A. M.; HÜTTER, R. Ametryne and prometryne as sulfur sources for bacteria. Applied and Environmental Microbiology, Washington, v. 43, p. $81-86,1982$.

COSTA, M. A. Biodegradação de ${ }^{14} \mathbf{C}$-ametrina em Areia Quartzosa com adição de palha de cana e solo rizosférico. Piracicaba : ESALQ, 1992. 107 p. Dissertação de Mestrado.

FREITAS, J. R.; NASCIMENTO FILHO, V. F.; VOSE, P. B.; RUSCHEL, A. P. Estimativa da atividade da microflora heterotrófica do solo TRE usando respirometria com Glicose- ${ }^{-14} \mathrm{C}$. Energia Nuclear e Agricultura, Piracicaba, v. 1, p. 123-130, 1979.

FÜHR, F. Non-extractable pesticides residues in soil. In: GREENHALG, R.; ROBERTS, T. R. Pesticide science and biotechnology. Oxford : International Union of Pure and Applied Chemistry, 1987. p. 381-389.

FURLAN, G. R. Efeito da queimada na adsorção, dessorção e mobilidade dos herbicidas 2,4-D, ametrina e trifluralina em dois solos da região Amazônica. Piracicaba : USP-CENA, 1992. 53 p. Dissertação de Mestrado.
LEHNINGER, A. L. Princípios de bioquímica. São Paulo : Sarvier, 1985. $725 \mathrm{p}$.

MARTINEZ CRUZ,A.; ALEMÉN, I.; BACH, T.; CALERO, B. J. Effects of irrigation with sugar factory waste water. II. Microflora associated to the carbon cycle. Ciencias de la Agricultura, Havana, v. 30, p. 118-127, 1987.

MATTIAZZO, M. E.; GLÓRIA, N. A. Effect of vinasse on soil activity. Water Science and Technology, Oxford, v. 19, p. 1293-1296, 1987.

MESQUITA, T. B.; RUEGG, E. F. Influência de agentes tensoativos na detecção da radiação beta. Ciência e Cultura, São Paulo, v. 36, p. 446-450, 1984.

MINHONI, M. T. A.; CERRI, C. C. Decomposição de vinhaça em solo sob diferentes níveis de umidade: liberação de $\mathrm{CO}_{2}$, formação de biomassa microbiana e imobilização do nitrogênio adicionado. Revista Brasileira de Ciência do Solo, Campinas, v. 11, p. 25-30, 1987.

NELSON, D. W.; SOMMERS, L. E. Total carbon, organic carbon, and organic matter. In: PAGE, A. L. (Ed.). Methods of soil analysis. 2. ed. Madison : American Society of Agronomy, 1982. pt 2, p. 539-579.

RAIJ, B. van; QUAGGIO, J. A. Métodos de análise de solo para fins de fertilidade. Campinas : Instituto Agronômico, 1983. 31 p. (IAC. Boletim Técnico, 81).

REIS, T. C. Variação da acidez do solo em resposta a adição de materiais orgânicos. Piracicaba : ESALQ, 1998. 65 p. Dissertação de Mestrado.

RODELlA, A. A.; ZAMBELlO JÚNIOR, E.; ORLANDO FILHO, J. Effects of vinasse added to soil on $\mathrm{pH}$ and exchangeable aluminum content. In: CONGRESS OF THE INTERNATIONAL SOCIETY OF SUGAR CANE TECHNOLOGISTS, 18., Havana, 1983. Proceedings... Havana : Universidad de La Habana, 1983. p. 189-214.

RODRIGUES, B. N.; ALMEIDA, F. S. Guia de herbicidas. Londrina : Instituto Agronômico do Paraná, 1995. $676 \mathrm{p}$.

WEBER, J. B. Mechanisms of adsorption of s-triazines by clay colloids and factors affecting plant availability. Research Review, Edinburgh, v. 32, p. 93-130, 1970.

YAMANE, V. K.; GREEN, R. E. Adsorption of ametryne and atrazine on an oxisoil, montmorillonite and charcoal in relation to $\mathrm{pH}$ and solubility effects. Soil Science Society of America Proceedings, Madison, v. 36, p. 58-64, 1972. 